\title{
Studies on Interaction of Essential Metal Ions with Bioactive Ligands
}

\author{
Brij Bhushan Tewari \\ Department of Chemistry, Faculty of Katural Sciences, University of Guvana, \\ P. O. Box 101110, Georgetown, Guyana, South America \\ Recened February 13, 2004
}

\begin{abstract}
Complexation reactions of nitrilotriacetate (NTA) and penicillamine with $\mathrm{Cu}^{\hat{-}^{-}}$and $\mathrm{Co}^{\hat{2}^{-}}$have been studied in solution phase using paper electrophoresis technique. The stability constants of the complexes $\mathrm{Cu}(\mathrm{II})$ nitrilotriacetate-penicillamine and $\mathrm{Co}(\mathrm{II})$-nitrilotriacetate-penicillamine have been found to be $6.64 \pm 0.03$ and $5.86 \pm 0.05$ (logarithm stability constant values). respectively at $35^{\circ} \mathrm{C}$ and ionic strength $0.1 \mathrm{M}$.
\end{abstract}

Key Words : Electrophoretic technique. Stability constants. Copper(II) complexes. Cobalt(II) complexes

\section{Introduction}

The complexation data involving body toxic or essential metal ions. bioactive ligand. nitrilotriacetate and penicillamine give insight into many physico-chemical processes. The most important reactions are the processes involving participation of the mercapto group and main biochemical aspects of these have been reviewed by Jocelyn. ${ }^{1}$ The extremely greater biological importance is attributed to the capabilities of the mercapto group to undergo various complex formation processes primary in non-haem iron proteins $^{2}$ and blue copper proteins. ${ }^{3}$ Sorensen ${ }^{4}$ has demonstrated the anti-inflammatory activity of copper $\mathrm{D}$ penicillamine. The significance of sulphur containing amino acids like penicillamine is enhanced by the fact that. in recent years. it has been utilized in comection with rheumatoid arthritis. Copper(II) and cobalt(II) metal ions have significant biomedical applications but are toxic at higher concentration. ${ }^{6.16}$ The average copper and cobalt content of a healthy human (body' weight $70 \mathrm{~kg}$ ) are $0.1 \mathrm{~g}$ and $0.001 \mathrm{~g}$. respectively: The recommended normal and toxic level of copper and cobalt elements per day' human diet are (0.5-6.0 mg: $20 \mathrm{mg}$ ) and $(0.005-1.8 \mathrm{mg}: 500 \mathrm{mg})$. respectively. ${ }^{17}$

The present electrophoretic technique is almost free from number of defects such as temperature during electrophoresis. capillary flow on paper. electroosmosis and adsorption. The technique is very convenient in use. It gives results in fair agreement with the accepted literature values. The stability constants of metal complexes can be very easily calculated by this technique. so the present electrophoretic technique have significant advantages over other methods reported in chenical literature for the determination of stability constants of metal complexes.

A search of literature indicated that no report is available on binary and mixed complexes of $\mathrm{Cu}$ (II)/Co(II) with nitrilotriacetate and penicillamine. In view of this, attempts were made to establish the optimum conditions for metalpenicillamine. metal-NTA and metal-NTA-penicillanine comiplex formation. In addition, present article describes a

Phone: +592-222-6004; Fax: +592-222-3596; e-mail: brijtewa yahoo.con paper electrophoretic method for the determination of the stability constants of these complexes.

\section{Experimental Section}

Instruments. Systronics (Naroda. India) paper electrophoresis equipment horizontalcum-vertical type. model 604. has been used. The apparatus consisted of a PVC moulded double tank vessel. In our laboratory significant change in the instrument has been made. Two hollow rectangular plates covered with thin polythene sheets have been used through which thermostated water is nun for controlling the temperature. The tanks were closed with a transparent PVC moulded lid. The whole assembly is tight. which prevent moisture changes. which may upset the equilibria in a paper strip. This assembly design thus keeps to a minimum the disturbing effects of evaporation from the unwanted liquid flow in the paper. Each electrolyte tank contains a separate electrode chamber. The auxillary unit is specially designed to operate either voltage mode or on current mode.

Elico (Hyderabad. India) model $\mathrm{L}_{\mathrm{l}-10}$ having glass and calomel electrode assembly and working on 220 Volts $/ 50 \mathrm{~Hz}$ established a. c. mains, were employed for $\mathrm{pH}$ measurements.

Chemicals. Metal perchlorate solutions were prepared by the precipitation of metal carbonates from their nitrates with sodium carbonate. which were washed with boiling water and treated with calculated amounts of $1 \%$ perchloric acid There were heated and filtered. The metal contents of the filtrates were determined and final concentration was kept at 0.005 M. A $0.1 \%$ (w/v) solution of 1-(2-pyridylazo)-2naphthol (PAN) (Merck, Darmstadt. Germany) in ethanol was used for detecting the metal ions. $0.005 \mathrm{M}$ glucose (BDH, AnalaR) solutions was prepared in water and used as an electro-osmotic indicator for the correction due to electroosmosis. A saturated aqueous solution $(0.9 \mathrm{~mL})$ of silver nitrate was diluted with acetone to $20 \mathrm{~mL}$. Glucose was detected by spraying with this silver nitrate solution and then with $2 \%$ ethanolic sodium hydroxide, when a black spot was formed.

Background electrolyte. Stock solution of $5.0 \mathrm{M}$ perchloric acid was prepared by its $70 \%$ solution (SDS, AnalaR 
grade) $2.0 \mathrm{M}$ sodium hydroxide (AnalaR grade) and $0.5 \mathrm{M}$ penicillamine $(\mathrm{BDH})$ solutions were prepared. A $0.01 \mathrm{M}$ nitrilotriacetate, solution was prepared from the compound obtained from $\Gamma_{\text {. }}$ Merck (Darmstadt. Germany). Fach solution was standardized using the appropriate method.

The background electrolytes (BGFs) used in the study of binary complexes were $0.1 \mathrm{M}$ perchloric acid and $0.01 \mathrm{M}$ penicillamine. For the study of mixed systems the BGFs used consisted of $0.1 \mathrm{M}$ perchloric acid, $0.001 \mathrm{M}$ NTA and various amounts of $0.01 \mathrm{M}$ penicillamine. The mixed system was maintained at $\mathrm{pH} 8.5$ by the addition of sodium bydroxide.

Procedure. Whatman No. 1 filter paper for chromatography was used for the purpose of electrophoresis. For recording observation of particular metal ion, two strips were spotted with the metal ion solution along with additional two spotted with glucose using $1.0 \mu \mathrm{L}$, pipette and then mounted on the insulated plate. Fach of the two electrolyte vessel was filled with $150 \mathrm{~mL}$, of background electrolyte containing $0.1 \mathrm{M}$ perchloric acid and $0.01 \mathrm{M}$ penicillamine. The paper become moistened with the background electrolyte solutions due to diffusion. The second insulated plate was placed on paper strips and then thermostated water $\left(35^{\circ} \mathrm{C}\right)$ was circulated in the plates to keep the temperature constant. The lid was then placed on the instrument to make it air tight. It was left for 10 minutes to insure wetting of strips. Subsecjuently a direct 200 Volts potential was applied between the electrodes. Clectrophoresis was carried for 60 minutes after which these strips were removed from the tank and dried. The metal ion and glucose spots were detected by specific reagents. The leading and tailing edge were measured from the marked centre point and the mean were taken. The distance moved by glucose was subtracted (in case of migration toward anode) to obtain correct path length. Migration towards anode and cathode were designated by negative and positive signs respectively.

[.lectropheretic observations on metal ions were recorded at various $\mathrm{pH}$ values of the background electrolyte obtained by adding $\mathrm{NaOH}$ solution. The ionic strength being maintained at $0.1 \mathrm{M}$. The observed mobility of migrant was calculated by using the formula.

$$
U=\frac{d}{x \cdot t}
$$

After applying the correction factor the observed mobility is given as

$$
U=\frac{d \pm d_{i}}{x \cdot t}
$$

Where $U=$ mobility of metal ion/complex ion; $d=$ mean of duplicate distance travelled by metal ion/complex ion: $d_{i}=$ mean of duplicate distance travelled by glucose spot; $x=$ field strength; $t=$ time for electrophoresis.

The protonation constants of pure penicillamine were determined by the same paper electrophoresis technique. The two paper strips were spotted with pure penicillamine along with two with glucose using $0.1 \mathrm{M}$ perchloric acid only in a background electrolyte. The electrophoresis was carried for 60 minutes as for metal ions. The electrophoretic speed was calculated and the speed of the metal ion/ penicillamine spots are reported with $\mathrm{pH}$ values. The individual speeds of the duplicate spots were found to be fairly equal.

\section{Results and Discussion}

(i) Metal-Penicillamine Binary Systems. The overall electrophoretic mobilities of metal ions as a function of $\mathrm{pH}$ are given in Figure 1. The first plateau corresponds to a region in which metal ions are uncomplexed. The second plateau in each instance (copper(II)-penicillamine and cobalt(1)-penicillamine) with zero mobility indicates the formation of $1: 1$ neutral complexes. With a further increase of $\mathrm{pH}$ the mobility decreases, giving rise to a third plateau lying in negative region, indicating an anionic nature of the metal-penicillamine complexes. In view of above observations, the complexation of metal ions with the penicillamine anion $\left[\mathrm{I}^{2-}\right]$ can be represented as

$$
\begin{gathered}
\mathrm{M}^{2 \cdot}+\mathrm{L}^{2-} \stackrel{K_{1}}{\longleftarrow} \mathrm{ML} \\
\mathrm{ML},-\mathrm{I}^{2-} \stackrel{K_{2}}{\hookrightarrow} \mathrm{Ml}^{2-},
\end{gathered}
$$

Where $\mathrm{M}^{2}-\mathrm{Cu}^{2}$ and $\mathrm{Co}^{2}$ ions; $\mathrm{L}^{2-}-$ penicillamine anion; $\mathrm{K}_{1}, \mathrm{~K}_{2}$ - first and second stability constants, respectively.

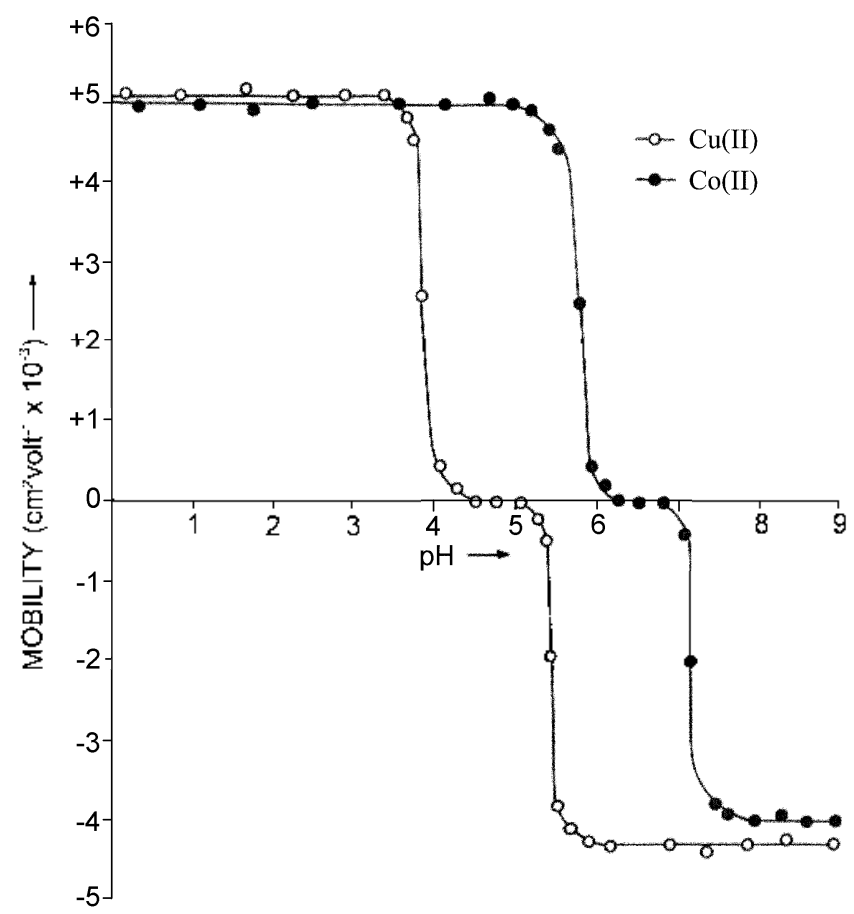

rigure I. Mobility curve for the M-penicillamine systems, $-=$ Cu(II)-penicillamine: $=$ Co(II)-penicillamine. Concentration of penicillamine $=0.01 \mathrm{M}$. Concestration of $\mathrm{Cu}(\mathrm{II})$ and $\mathrm{Co}(\mathrm{II})=$ $0.005 \mathrm{M}$. 
The metal spot on the paper is thus a conglomeration of uncomplexed metal ions, 1 : 1 complex and $1: 2$ complex. The spot is moving under the influence of electric field and the overall mobility " $U$ " is given by equation"

$$
U=\sum_{n} u_{n,} f_{n}
$$

Where $u_{t}$ and $f_{n}=$ mobilities and mole fractions of particular complex species, respectively.

Fquation (3) is transformed into the following useful form of taking into consideration the different equilibria

$$
U-\frac{u_{0}+u_{1} K_{1}\left|\mathrm{~L}^{2-}\right|+u_{2} K_{2}\left|\mathrm{~L}^{2-}\right|^{2}}{1\left|K_{1}\left[\mathrm{~L}^{2-}\right]\right| K_{1} K_{2}\left[\mathrm{~L}^{2-}\right]^{2}}
$$

Where $u_{1}, u_{1}$, and $t_{2}=$ mobilities of the uncomplexed metal ions, $1: 1$ and $1: 2$ metal complexes, respectively.

The protonation constants of pure penicillamine $\left(\mathrm{pk}_{1}=\right.$ $1.90 ; \mathrm{pk}_{2}=7.85 ; \mathrm{pk}_{3}=10.55$ ) are obtained by same paper electrophoretic technique. The mode of protonation of pure penicillamine can be represented as<smiles>CC(C)(S)C([NH3+])C(=O)O</smiles>

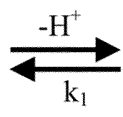<smiles>CC(C)(S)[C@H]([NH3+])C(=O)[O-]</smiles><smiles>CC(C)(S)C(N)C(=O)[O-]</smiles>

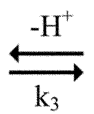<smiles>CC(C)(S)C(N)C(=O)[O-]</smiles>

For calculating first stability constant, $K_{1}$, the region between first and second plateau is pettinent. The overall mobility will be equal to the arithmetic mean of the mobility of uncomplex metal ion, $z_{0}$, and that of lirst complex, $u_{1}$, at a pl[ where $K_{1}-1 /\left|\left(\mathrm{CH}_{3}\right)_{2} \mathrm{C}(\mathrm{S}) \mathrm{Cl}\left(\mathrm{NH}_{2}\right) \mathrm{COO}\right|$. With the help of protonation constants of penicillamine, the concentration of the liganding penicilamine $\mathrm{L}^{2} \mid$ is calculated

$$
\left[\mathrm{L}^{2-}\right]=\frac{\left[\mathrm{L}_{1}\right]}{\left.\left.1+[\mathrm{H}] / k_{3}+\mid \mathrm{H}\right]^{2} / k_{2} k_{3}+\mid \mathrm{H}\right]^{3} / k_{1} k_{2} k_{3}}
$$

Where $\left[\mathrm{L}_{T}\right]-$ total concentration of penicillamine; $k_{1}, k_{2}$ and $k_{s}-$ first, second and third dissociation constants of pure penicillamine, respectively.

The stability constant, $K_{2}$, of second complex can be calculated by taking into consideration the region between the second and third plateat of the mobility curve. The calculated values of $K_{1}$ and $K_{2}$ are given in Table I.

(ii) Metal-Nitrilotriacetate Binary Sytems. Coordination of metal ions with NTA has been studied widely by workers. ${ }^{19.20}$ The overall mobility of the metal spots in the presence of NTA at different $\mathrm{pH}$ values is presented in Figure 2. The mobility at the last plateau is negative in each case showing the anionic nature of metal-NTA complexes. The stability constant, $K_{3}$, of these binary complexes were calculated by using the same method as described for metalpenicillamine system. The complexation may be represented as

$$
\mathrm{M}^{2-}+\mathrm{NTA}^{3-} \stackrel{K_{3}}{\leftrightarrows}[\mathrm{M}-\mathrm{NTA}]^{-}
$$

The calculated values of $K$ : are given in Table I.

(iii) Metal-NTA-Penicillamine Mixed Systems. The study of mixed complexes has been carried in the presence of $0.001 \mathrm{M} \mathrm{NTA}$ with progressive addition of secondary

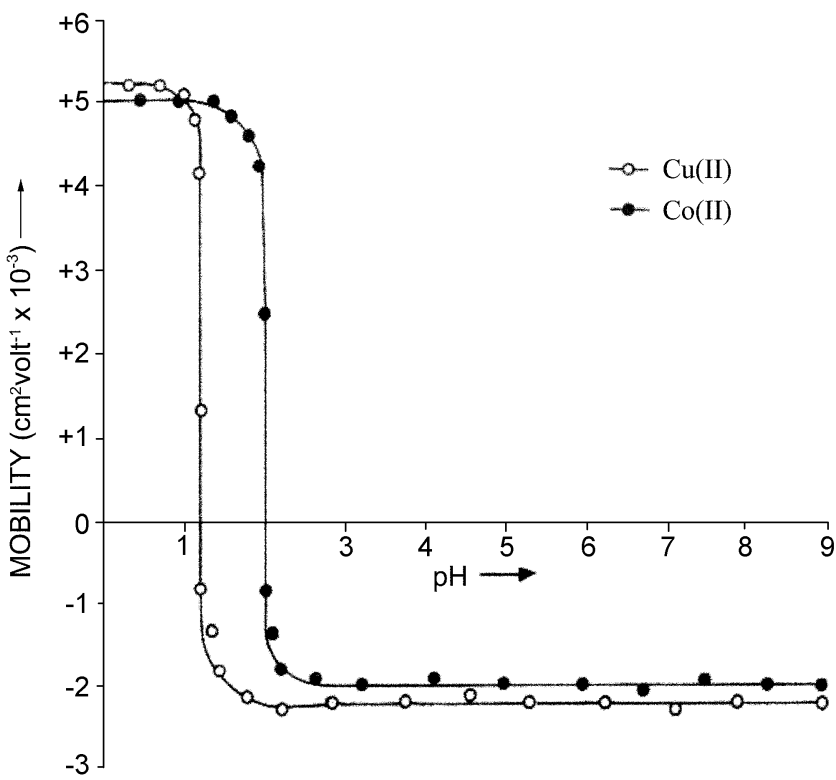

Figure 2. Mobility curve for the M-NTA systems. : = Cu(II)-NTA; - Co(II)-NTA. Concentration of NTA $=0.001$ M. Concentration of Cufl]) and Co(II) $0.005 \mathrm{M}$.

Table 1. Stability constants of complexes of copper(II) and cobalt(II)

\begin{tabular}{cccccc}
\hline & & \multicolumn{5}{c}{ Stability constants } \\
\cline { 3 - 6 } Values & Metal ions & $\mathrm{a}$ & $\mathrm{b}$ & $\mathrm{c}$ & $\mathrm{d}$ \\
\hline Calculated & $\mathrm{Cu}^{2+}$ & $12.61-0.04$ & $9.70 \perp 0.07$ & $12.37 \pm 0.04$ & $6.64 \perp 0.03$ \\
(this work) & $\mathrm{Co}^{2+}$ & $8.90 \perp 0.06$ & $6.17 \perp 0.03$ & $10.39 \pm 0.03$ & $5.86 \perp 0.05$ \\
\hline
\end{tabular}

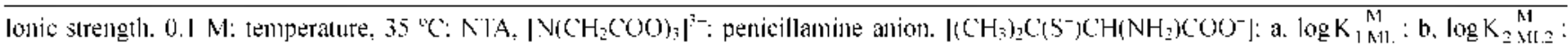

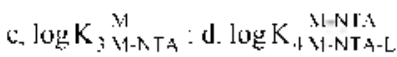




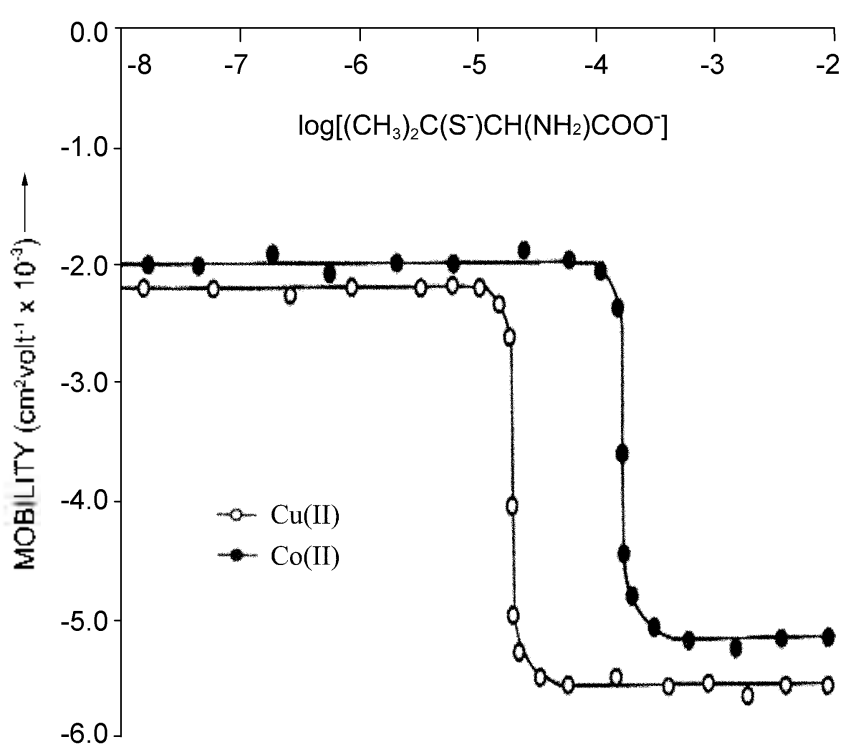

Figure 3. Mobility curve for the M- NTA-penicilamine systems. $=\mathrm{Cu}(\mathrm{II}) \mathrm{N}$ 'N-penicillamine: $\boldsymbol{\theta}=\mathrm{Co}(\mathrm{II})-\mathrm{NIA}$-penicillamine. Concentration of $\mathrm{N}^{\mathrm{T}} \mathrm{C}=0.001 \mathrm{M}$. Concentration of $\mathrm{Cu}(\mathrm{II})$ and $\mathrm{Co}(\mathrm{II})=0.005 \mathrm{M}$. pH 8.5 was maintained bs $\mathrm{NaOH}$ solution.

ligand penicillamine to the background electrolyte fixed at $\mathrm{pH}$ 8.5. The plot of mobility against the logarithm of the concentration of added penicillamine give a curve containing two plateatus (Figure 3), It is inferred that moiety in the last plateau is due to coordination of penicillamine anion to the [M-NTA] $]^{-}$moiety, resulting in the formation of a $1: 1: 1$ metal-NTA-penicillamine mixed complex

$$
[\mathrm{M}-\mathrm{NTA}]^{-}+\mathrm{L}^{2-} \stackrel{K_{4}}{\leftrightarrows}[\mathrm{M}-\mathrm{NTA}-\mathrm{L}]^{3-}
$$

where $K_{4}=$ stability constants of mixed complexes.

In this electrophoretic study, the transformation of a simple complex into a mixed complex takes place, hence overall mobility "U" of this complex is given as

$$
U-\frac{u_{0}+u_{1} K_{4}\left[\left(\mathrm{CH}_{3}\right)_{2} \mathrm{C}(\mathrm{S}) \mathrm{CH}\left(\mathrm{NH}_{2}\right) \mathrm{COO}\right]}{1 \mid K_{4}\left[\left(\mathrm{CH}_{3}\right)_{2} \mathrm{C}\left(\mathrm{S}^{-}\right) \mathrm{CH}\left(\mathrm{NH}_{2}\right) \mathrm{COO}^{-}\right]}
$$

Where $t_{k}$ and $t_{1}=$ mobilities of metal-nitrilotriacetate and metal-nitrilotriacetate-penicillamine complexes, respectively.

The concentration of penicillamine anion at $\mathrm{pH} 8.5$ was calculated. $K_{4}$ is obviously equal to $1 /\left[\left(\mathrm{CH}_{3}\right)_{2} \mathrm{C}_{\left(\mathrm{S}^{-}\right)}\right.$ $\mathrm{CH}\left(\mathrm{NH}_{2}\right) \mathrm{COO}^{-}$. All these values of $K_{4}$ are given in lable 1 .

The logarithm of formation constants $\left(\log K_{M L-N[A}^{M L}\right)$ for the interaction

$$
\mathrm{ML} \cdot \mathrm{NTA} \leftrightarrows \mathrm{ML}-\mathrm{NTA}
$$

can be computed by relation

$$
\log K_{\mathrm{ML}-\mathrm{NTA}}^{\mathrm{ML}}=\log \beta_{\mathrm{N}-\mathrm{VIA-L}}-\log K_{1 \mathrm{ML}}^{\mathrm{M}}
$$

Table 2. Stability constants of complexes of copper(II) and cobalt(1])

\begin{tabular}{ccccc}
\hline & & \multicolumn{4}{c}{ Stability constants } \\
\cline { 3 - 5 } Values & Metal jons & $\mathrm{e}$ & $\mathrm{f}$ & $\mathrm{g}$ \\
\hline Calculated & $\mathrm{Cu}^{2-}$ & $19.01 \pm 0.07$ & $5.97 \pm 0.07$ & $6.40 \pm 0.11$ \\
(this work) & $\mathrm{Co}^{2-}$ & $16.25 \pm 0.08$ & $3.04 \pm 0.11$ & $7.35 \pm 0.14$ \\
\hline
\end{tabular}

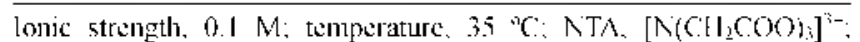
penicillamine anion, $\left.\mathrm{l}(\mathrm{CI})_{3}\right)_{2}\left(S^{-}\right) \mathrm{CI}\left(\mathrm{NII}_{2}\right) \mathrm{COO}^{-} \mid$: e. $\log \beta_{\mathrm{M}-\mathrm{NTA} \text { L. }}$

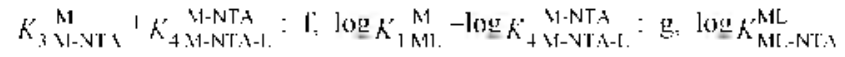

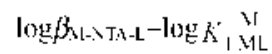

$$
\log \beta_{\mathrm{N}-\mathrm{VTA}-\mathrm{J} .}-\log K_{3} \mathrm{M}_{\mathrm{M}-\mathrm{NTA}}+\log K_{4 \mathrm{M}-\mathrm{NTA} \mathrm{M}-\mathrm{I}}
$$

The calculated values of $\log \left(\log K_{\mathrm{M} \text {. NTA }}^{\mathrm{M} \text {. }}\right)$ are given in Table 2. It is clear from Table 2 that NTA does have strong affinity to metal ions in comparison to penicillamine.

\section{Concluding Remark}

It may be concluded from these studies that copper(ll) and cobalt(1) metal ions are essential for biological systems but as such they are toxic the nitrilotriacetate and penicillamine can be used to reduce the levels of these metal ions in living cells.

\section{References}

1. Jocelyn. C. I'. Biochenistm: of SH Gomp: Academic P'ress: Lothdon and New York. 1972.

2. Moors. R. Gi.: Willians. P. I. R. Coond. Chem. Re's. 1976. /S. 125.

3. V.ट. A. J. Sintet. Bonding (Berlin) 1975. 23. 11.

4. Sorensen. R. J. J. Hed. (hem. 1976. 19. 135

5. l'erretl. D.: Snedden. W.: Slephena. D. A. Biochem. Phamacol. 1976. 25. 259 .

6. Jimerez. A.: Planells. Г.: Ruperes. P.: Calisto, Г. S. J. Agrt. Food Chem. 1997, 45, 4023.

7. Puk. J.-L: (Braiml. (. M.: Davies. M. I.: I)antes. I. W. J. Biol (\%)m. 1998. 273. 22921.

8. Dallinger. R.: Berger. B.: Hunjiker. H.: Kagi. J. H. R. Noture 1997. 388.237 .

9. Weaver, (i. W: I eeper, F, J.: Battersbs, A, R:: Blanche, F.: Thibant. D): Debusscht. 1. Chem. Comman. 1991. /4.976.

10. Thibalut. I): Kiuchi. 1.: Debussche. 1..: I.eeper. I. J.: I3lanche. I: (hem. Commun. 1992. ? 139.

1]. Beyreuther. K.: Master. C. Aatme 1997. 289. 677.

12. Buill. P. C.: Thomas. G. R.: Rommens. J. M.: Forbes. J. R.: Cox. D. W. Nemme Genet 1993, 5,327 .

13. Wang. D.: Munoz. D, (i, J. Neuropathol Exp. Aeurol. 1995. 54 548 .

14. Hartman. H. A.: Evenson. M. A. Wed. Hpothesis 1992. 34. 75.

15. Beckman. J. S.: Carson. M.: Sinith. C. D.: Kippenol. W. H. Namw? 1993. 36 f. 584 .

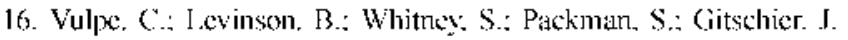
Hallowe Genet 1993, 3.7.

17. Baneriea D. Everymants Sci. 1995. 29.176.

18. Vichol. J. J Am. (hem. Soc. 1950.7?. 2367.

19. Sharma. G.: landon. J. H. J. Inorg. Nucl. Chem. 1970. 32. 1273.

20. Rabensticn. D. L.: Kulc. R. J. I. th. ('hem. Soc. 1969. 91. 2492. 